\title{
Оценка и моделирование развития промышленности ЦЧР в постсоветское время
}

\author{
А. Э. Крупко ${ }^{凶}$, Ю. М. Фетисов \\ Воронежский государственный университет, Российская Федераиия \\ (394018, г. Воронеж, Университетская пл., 1)
}

\begin{abstract}
Аннотация: Цель работы заключается в выявлении особенностей, тенденций и факторов развития промышленности Центрально-Черноземного района. Недостаточно высокий уровень промышленности ЦЧР и негативные многолетние тенденции ее развития требуют глубокого анализа внутренних причин развития экономики района. Материалы и методы. Для достижения поставленной цели использовались сравнительный, структурный, статистический, математико-статистический и аналитический методы исследования. Была использована статистическая информация, представленная в официальных изданиях Федеральной службы государственной статистики - «Регионы России» за 20032019 годы. Для выполнения расчетов статистические данные были обобщены, систематизированы и структурированы. При моделировании факторов и тенденций развития промышленности мы использовали традиционные виды регрессионных моделей с их расширенной экономической интерпретаций. Математическое моделирование и экономическую интерпретацию его результатов были произведены на основе анализа взаимосвязей между объемами налогов, ВРП, промышленности, сельского хозяйства, торговли и строительства ЦЧР. Результаты. Анализ коэффициентов вариации показывает, что именно промышленность была самой стабильной отраслью хозяйства в 2000-е годы. В моделях, определяющий развитие налогов, влияние промышленности на налоговый потенциал было преобладающим. Во всех моделях оценки факторов на развитие ВРП, значение промышленности было намного выше по сравнению с другими отраслями, кроме торговли. Учитывая реалии современного сложного времени, на основе нашей работы можно сделать вывод о том, что экономически наиболее эффективным направлением инвестиционного развития Центрально-Черноземного района является преимущественное развитие промышленного сектора хозяйства. Основные направления реиндустриализации хозяйства ЦЧР по нашему мнению должны быть направлены на повышение качества и добавленной стоимости продукции АПК, а также ускоренного развития отраслей машиностроения и легкой промышленности, обеспечивающих местные региональные и локальные рынки.
\end{abstract}

Ключевые слова: Центрально-Черноземный район, регрессия, корреляция, интерпретация, налоги, валовой региональный продукт, промышленность, сельское хозяйство, торговля, строительство.

Для цитирования: Крупко А.Э., Фетисов Ю.М. Оценка и моделирование развития промышленности ЦЧР в постсоветское время // Вестник Воронежского государственного университета. Серия: География. Геоэкология, 2020, № 2, с. 66-74. DOI: https://doi.org/10.17308/geo.2020.2/2888

\section{ВВЕДЕНИЕ}

Внешние угрозы и внутренние проблемы развития хозяйства требуют сбалансированного состояния страны. Сбалансированность является синонимом относительно устойчивого состояния региональных общественных систем [11]. В насто- ящее время наблюдается дисбаланс в их развитии именно из-за проблем и деградации хозяйственного комплекса. Деградации малоэффективных отраслей промышленности обусловили асимметрию достаточно сбалансированной территориально-отраслевой структуры всего хозяйства района

(C) Крупко А.Э., Фетисов Ю.М., 2020

E-mail: glomer-a@mail.ru

Контент доступен под лицензией Creative Commons Attribution 4.0 License. 


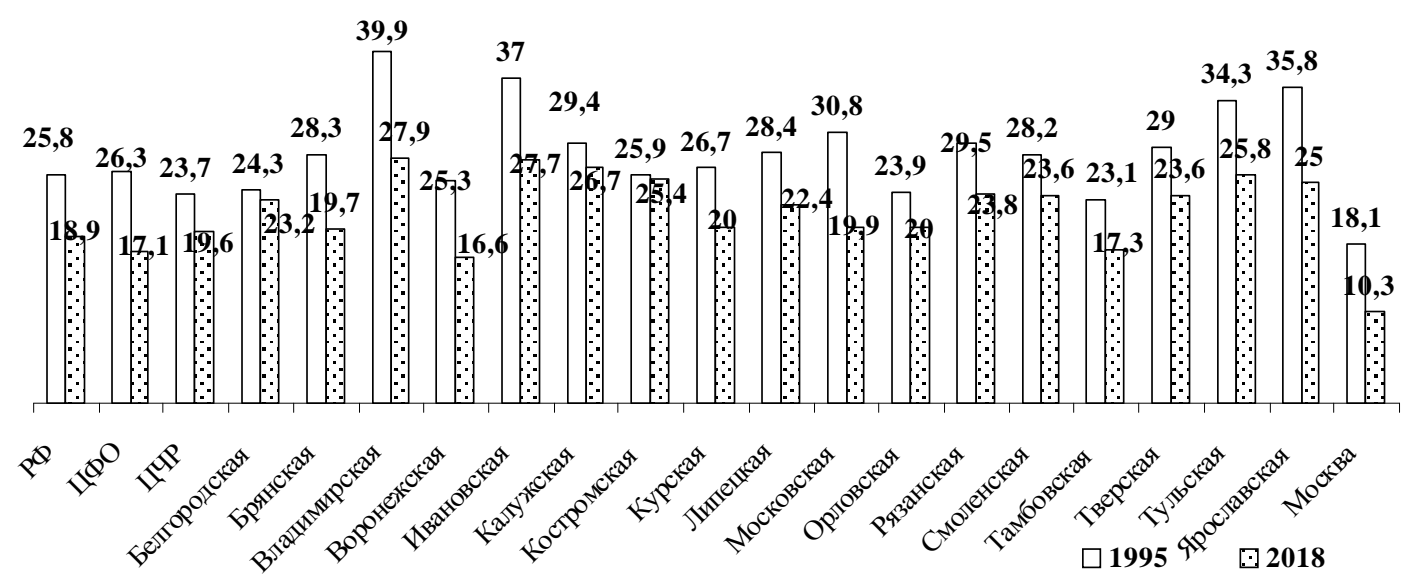

Puc. 1. Доля промышленных работников в занятом населении, \% (Построен по [6, 9])

[Fig. 1. The share of industrial workers in the employed population, \% (Built on [6,9])]

и ухудшили целостность его промышленного комплекса. Если раньше, при стабильной внешнеполитической обстановке, проблемы производственной сферы были не такими острыми, то сейчас ситуация стала исключительно опасной. Санкции, особенно возможный запрет на поставку высокотехнологической продукции, угрожают безопасности страны. Уровень самодостаточности регионов ЦЧР, как и страны в целом, снизился, а технологическое отставание выросло. Для примера, в микроэлектронике в советское время мы отставали от ведущих стран мира примерно на 4-5 лет, в настоящее время до 15-30 лет (в зависимости от видов электронной продукции). ЦЧР (как и в РФ) преобладают технологии четвертого уклада - более $50 \%$, на пятый уклад приходится около $10 \%$, а на третий около $30 \%$ всех технологий. Технологии шестого технологического уклада пока составляют около $1 \%$ [4]. Район завис на четвертом цикле Кондратьева из-за экстенсивного развития в 70-е годы, застоя 80-х гг. и системного кризиса 90-х годов. Для района характерно преобладание в производственной сфере АПК и черной металлургии.

\section{МАТЕРИАЛЫ И МЕТОДЫ ИССЛЕДОВАНИЯ}

Исследование развития промышленного производства ЦЧР в постсоветское время нами проводилось в сравнении с аналогичными показателями других регионов ЦФО, ЦФО в целом и РФ. Для достижения поставленной цели были использованы сравнительный, структурный, статистический, математико-статистический и аналитический методы исследования. Была использована статистическая информация, представленная в официальных изданиях Федеральной службы государственной статистики - «Регионы России» за 2003-
2019 годы. Для выполнения расчетов статистические данные были обобщены, систематизированы и структурированы. При моделировании факторов и тенденций развития промышленности мы использовали традиционные виды регрессионных моделей с их расширенной экономической интерпретаций.

В последние пятьдесят лет экономически развитые страны вступили в стадию постиндустриального развития, что ярко отразилось в структуре хозяйства этих стран, где стали лидировать третичные отрасли. В первой половине пятого цикла казалось, что именно он является вершиной развития человечества. Развитые страны за счет «ножницы» цен на высоко- и низко-технологические виды продукции, высокой производительности труда, кардинального улучшения природопользования достигли относительно устойчивого состояния. В последние годы стало очевидно, что постиндустриальное развитие является тупиком человечества: по прогнозам европейских ученых к середине 21 века занятость в странах Западной Европы будет составлять не более $20 \%$ трудоспособного населения, что вызовет глубочайшие социальные потрясения. Именно поэтому многие страны, особенно США, где доля занятых в обрабатывающей промышленности составляет лишь $8 \%$ всех занятых, пытаются проводить политику реиндустриализации. В условиях РФ и ЦЧР, где наблюдается намного более низкая производительность труда, тенденция сокращения численности занятых в производственном секторе хозяйства является еще более негативной.

В настоящее время доля занятых во всех отраслях промышленного производства в целом очень мала (рис. 1). 
Структура ВРП регионов ЦЧР, \% (Составлена по [6-9])

[Table 1. The GRP structure of the Central Black Soil regions, \% (Compiled by [6-9])]

\begin{tabular}{|c|c|c|c|c|c|c|c|c|c|c|c|c|}
\hline & \multicolumn{2}{|c|}{$\begin{array}{c}\text { Сельское } \\
\text { хозяйство / } \\
\text { Agriculture }\end{array}$} & \multicolumn{2}{|c|}{$\begin{array}{c}\text { Промыш- } \\
\text { ленность / } \\
\text { Industry }\end{array}$} & \multicolumn{2}{|c|}{$\begin{array}{c}\text { Строитель- } \\
\text { ство / } \\
\text { Building }\end{array}$} & \multicolumn{2}{|c|}{$\begin{array}{l}\text { Торговля / } \\
\text { Trade }\end{array}$} & \multicolumn{2}{|c|}{$\begin{array}{c}\text { Транспорт и } \\
\text { связь / } \\
\text { Transport } \\
\text { and } \\
\text { communica- } \\
\text { tions } \\
\end{array}$} & \multicolumn{2}{|c|}{$\begin{array}{c}\text { Прочие / } \\
\text { Other }\end{array}$} \\
\hline & 2005 & 2017 & 2005 & 2017 & 2005 & 2017 & 2005 & 2017 & 2005 & 2017 & 2005 & 2017 \\
\hline $\begin{array}{l}\text { Белгородская / } \\
\text { Belgorod }\end{array}$ & 11,6 & 18,1 & 48,2 & 37,3 & 6,6 & 6,4 & 13,6 & 14,3 & 6,5 & 6 & 31,5 & 17,9 \\
\hline \begin{tabular}{|l} 
Bopoнежская / \\
Voronezh
\end{tabular} & 10,4 & 14,4 & 25,1 & 18,2 & 5,8 & 9,1 & 21,4 & 19 & 10,4 & 8,7 & 26,9 & 30,6 \\
\hline \begin{tabular}{|l|} 
Kурская / \\
Kursk \\
\end{tabular} & 15,1 & 17,5 & 47,8 & 35,9 & 4 & 5,6 & 8,3 & 10,4 & 8,5 & 5,8 & 16,3 & 24,8 \\
\hline \begin{tabular}{|l|} 
Липецкая / \\
Lipetsk
\end{tabular} & 7,1 & 11,3 & 58,8 & 42,6 & 6,5 & 7,1 & 10,4 & 9,7 & 5,3 & 6,6 & 11,9 & 22,7 \\
\hline $\begin{array}{l}\text { Тамбовская / } \\
\text { Tambov }\end{array}$ & 15,5 & 21,7 & 20,2 & 15,3 & 7,7 & 13,8 & 23,1 & 16,5 & 13,2 & 9,2 & 20,3 & 23,5 \\
\hline ЦЧР / GBR & 11,1 & 16,1 & 42,3 & 29,9 & 6,1 & 8,0 & 14,9 & 14,6 & 8,1 & 7,2 & 17,4 & 24,2 \\
\hline
\end{tabular}
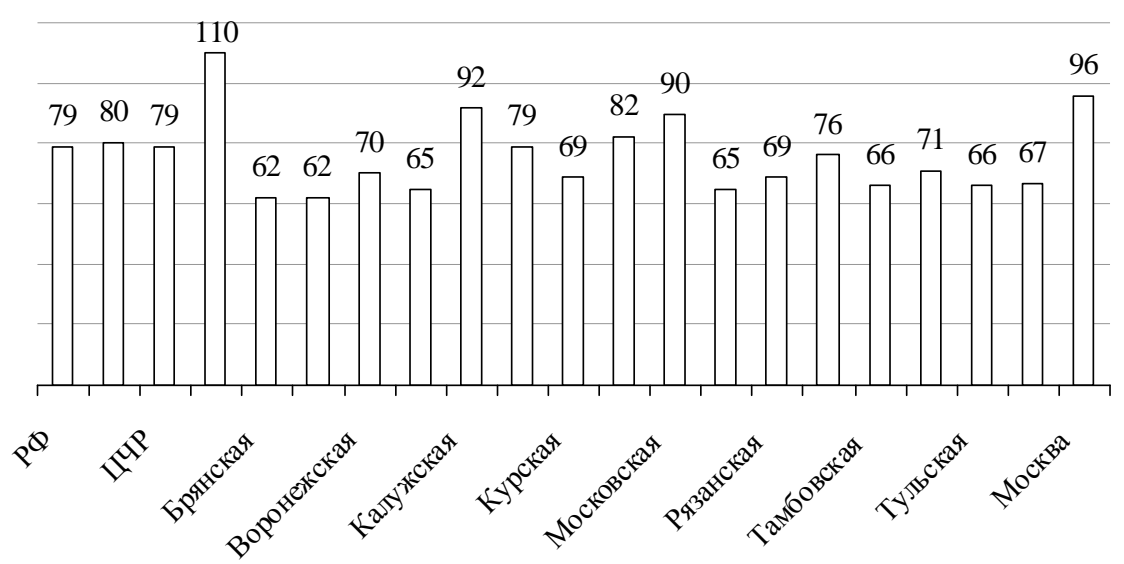

Puc. 2. Динамика численности занятых в промышленности за 1995-2018 годы, \% (Построен по [6, 9])

[Fig. 2. The dynamics of the number of people employed in industry in 1995-2018, \% (Built on [6,9])]

Воронежская и Тамбовская области в ЦФО (без учета Москвы) занимают последние места по отношению промышленных работников к общей численности занятого населения. Динамика численности занятых в промышленности во всех регионах ЦФО (кроме Белгородской области) отрицательная (рис. 2). С одной стороны процесс сокращения работников связан с ростом производительности труда, а с другой, неподготовленная и неграмотная приватизация без создания соответствующего финансово-экономического механизма привела к краху многих предприятий. Это определило снижение диверсификации экономики и крайне большую зависимость рынка района от импорта. С переходом на рыночные отношения произошли изменения в структуре ВРП, обусловленные преимущественным развитием наиболее выгодных отраслей с быстрой оборачиваемостью капитала и более эффективной высокой фондоотдачей $[4,13]$.

Во многом деиндустриализация экономики и глубокий промышленный кризис были связаны с инвестиционной политикой первой половины рыночного времени. Инвестиции поступали не в производственный сектор экономики, а в отрасли непроизводственной сферы с быстрым оборотом капитала. Поэтому, несмотря на значительный рост инвестиций в АПК ЦЧР, в последнее десятилетие доля промышленности в ВРП во всех регионах 
Основные показатели экономического развития ЦЧР (Составлена по [6-9])

[Table 2. The main indicators of the economic development of the Central Black Soil region (Compiled by [6-9])]

\begin{tabular}{|l|c|c|c|c|c|c|c|c|c|c|c|c|c|}
\hline & 2005 & 2006 & 2007 & 2008 & 2009 & 2010 & 2011 & 2012 & 2013 & 2014 & 2015 & 2016 & 2017 \\
\hline Налоги / Тахеs - $y$ & 79 & 97 & 121 & 154 & 134 & 167 & 199 & 209 & 218 & 231 & 251 & 269 & 297 \\
\hline ВРП / GRР - $x_{1}$ & 574 & 708 & 904 & 1153 & 1128 & 1331 & 1673 & 1854 & 2004 & 2320 & 2603 & 2718 & 2837 \\
\hline $\begin{array}{l}\text { Промышленность / } \\
\text { Industry } x_{21}\end{array}$ & 559 & 667 & 827 & 1050 & 904 & 1202 & 1460 & 1548 & 1590 & 1778 & 2104 & 2241 & 2445 \\
\hline $\begin{array}{l}\text { Сельское хозяйство / } \\
\text { Аgriculture - } x_{22}\end{array}$ & 125 & 145 & 200 & 264 & 281 & 279 & 392 & 459 & 515 & 621 & 774 & 792 & 895 \\
\hline $\begin{array}{l}\text { Торговля / } \\
\text { Trade - } x_{23}\end{array}$ & 247 & 306 & 396 & 1064 & 1207 & 673 & 801 & 944 & 1064 & 1207 & 1318 & 1391 & 1461 \\
\hline $\begin{array}{l}\text { Строительство / } \\
\text { Вuilding - } x_{24}\end{array}$ & 52 & 67 & 103 & 136 & 124 & 149 & 199 & 231 & 239 & 247 & 302 & 291 & 304 \\
\hline
\end{tabular}

района, особенно в Тамбовской и Воронежской областях, сократилась (таблица 1).

В Воронежской области доля торговли в ВРП даже выше удельного веса промышленности. Среди субъектов Центрально-Черноземного экономического района, в наибольшей степени производительные силы получили развитие в Белгородской и Воронежской областях. Воронежская область, обладая самой большой численностью рабочей силы и крупнейшими основными фондами в экономическом районе, уступает Белгородской области по эффективности их использования и социальной ориентированности [1].

Известно, что именно промышленность является ключевой отраслью, которая определяет уровень развития российских регионов. Именно в ней и в сельском хозяйстве наблюдается максимальный мультипликаторный эффект и формируются цепочки занятости (одно место в промышленном производстве может дать дополнительно от 3 до 25 мест в смежных отраслях хозяйства). Более прибыльные в краткосрочной перспективе отрасли не обеспечивают экономическую, продовольственную и технологическую безопасность страны и ее регионов. Рынок ЦЧР в исключительно высокой степени зависит от продукции других регионов страны и импорта (за исключением пищевой промышленности). Для оценки социальноэкономической стабильности аграрно-индустриального региона В.И. Федотовым, С. А. Куролапом, Ю.А. Нестеровым был предложен коэффициент самодостаточности $\left(K_{c}\right)$ показывающий, в каком соотношении находятся нормативные (теоретические) социально-экономические показатели и показатели реально произведенной продукции. В частности, коэффициент самодостаточности потребления $K_{c . n m}$ равен соотношению физиологичес- кой нормы потребления основных продуктов питания к количеству произведенного продовольствия в регионе в расчете на 1 человека [12]. В настоящее время наблюдается значительный рост производства продовольствия, поэтому по многим видам продуктов в ЦЧР наблюдается избыток продукции, особенно по сахару и растительному маслу $-K_{c . n m}$ меньше 0,1 [2]. При этом собственной продукцией легкой промышленности район обеспечен примерно на $20 \%$, а многие виды машиностроительной продукции бытового потребления в ЦЧР в отличие от советского времени практически не производятся. В 80-е годы (по нашим расчетам) объем производства потребительской продукции в Воронежской области превышал объем средней зарплаты.

В целом эффективность всего хозяйства ЦЧР страдает из-за избыточного развития относительно выгодных отраслей. Мы провели анализ развития основных отраслей хозяйства ЦЧР в постсоветское время, а регрессионный анализ с 2005 года. Это был первый год перехода к новой системе отчетности в рамках СНС. К этому времени экономический и промышленный кризисы закончились, наблюдался рост промышленного производства, но негативные тенденции оставались и остаются. Регрессионный анализ позволяет с определенным допуском определить главные направления оптимизации экономики района.

В данной статье мы использовали традиционную регрессионную модель, при этом нами была совершена попытка выйти за пределы обычной ее экономической интерпретации. Математическое моделирование и экономическую интерпретацию его результатов мы произвели на основе анализа взаимосвязей данных в два этапа. 
Коэффициенты регрессионных моделей

[Table 3. The coefficients of regression models]

\begin{tabular}{|l|c|c|c|c|c|c|c|c|c|c|}
\hline & $v_{x_{2 i}}$ & $a_{0}$ & $a_{1}$ & $a_{2}$ & $\ni_{1}$ & $\ni_{2_{i}}$ & $d_{x_{1}}$ & $d_{x_{2 i}}$ & $Q_{x_{1}}$ & $Q_{x_{2 i}}$ \\
\hline $\begin{array}{l}\text { Налоги, ВРП, } \\
\text { промышленность / } \\
\text { Тахеs, GRP, Industry }\end{array}$ & 43,23 & 33,28 & 0,017 & 0,088 & 0,154 & 0,667 & 0,195 & 0,790 & 0,072 & 0,289 \\
\hline $\begin{array}{l}\text { Налоги, ВРП, сельское } \\
\text { хозяйство / } \\
\text { Тахеs, GRP, agriculture }\end{array}$ & 58,80 & 31,63 & 0,1186 & $-0,100$ & 1,066 & $-0,236$ & 1,352 & $-0,371$ & 0,495 & $-0,139$ \\
\hline $\begin{array}{l}\text { Налоги, ВРП, торговля / } \\
\text { Тахеs, GRP, trade }\end{array}$ & 50,44 & 38,35 & 0,120 & $-0,062$ & 1,074 & $-0,279$ & 1,362 & $-0,383$ & 0,499 & $-0,141$ \\
\hline $\begin{array}{l}\text { Налоги, ВРП, } \\
\begin{array}{l}\text { строительство / } \\
\text { Тахеs, GRР, соnstruction }\end{array}\end{array}$ & 47,03 & 42,83 & 0,049 & 0,331 & 0,437 & 0,334 & 0,554 & 0,427 & 0,203 & 0,157 \\
\hline
\end{tabular}

На первом этапе было проведено моделирование и интерпретация взаимосвязей между налогами $(y)$, ВРП $\left(x_{1}\right)$, промышленности, сельского хозяйства, торговли и строительства $-x_{2}$. Результативным показателем явился объем налогов, факторными ВРП, объемы продукции промышленного производства, сельского хозяйства, оборота торговли и объема строительных работ.

Были определены множественные регрессии зависимость $y$ от $x_{1}$ и поочередно от четверых факторов $x_{2}$ по данным таблицы 2.

Сначала были рассчитаны частные коэффициенты корреляции между результативным и факторными показателями, затем коэффициенты вариации и коэффициенты уравнений регрессии вида:

$$
y_{1,2, \ldots, k}=a_{0}+a_{1} x_{1}+a_{2} x_{2}+E+a_{k} x_{k} \quad[3,5,10]
$$

Отсюда для налогов, ВРП и промышленности регрессионная модель имеет следующий вид: $\hat{y}_{1,2, \ldots, k}=33,28+0,017 x_{1}+0,088 x_{21}$.

Для остальных уравнений коэффициенты регрессии (таблица 3 ).

\section{ОБСУЖДЕНИЕ РЕЗУЛЬТАТОВ}

Коэффициент вариации налогов $\left(v_{y}=36,23\right)$ в ЦЧР за 2005-2018 годы был меньше по сравнению с факторными показателями, что характеризует относительно стабильное состояние налоговой системы ЦЧР. Коэффициент вариации ВРП $\left(v_{x_{1}}=46,47\right)$ был больше, чем $v_{x_{21}}$ - промышленности (таблица 3), но меньше по сравнению с другими отраслями. Поэтому именно промышленность была самой стабильной отраслью хозяйства в 2000-е годы.

Экономический анализ или интерпретация данной модели является основной целью нашего ис- следования и одним из главных аспектов корреляционно-регрессионного моделирования. Для этого нужно было рассчитать коэффициенты эластичности, детерминации, $Q(\kappa в a)$ - коэффициент влияния факторных признаков на результативный.

Частный коэффициент эластичности $\ni_{x_{i}}=a_{i} \cdot \frac{\overline{x_{i}}}{\bar{y}}$, показывает на какую часть процента меняется величина результативного признака при изменении факторного признака на $1 \%$. Его значение зависит от соотношений средних факторных и результативных признаков и соответствующих коэффициентов регрессии. В данной модели максимальный коэффициент эластичности характерен для промышленности $Э_{2_{1}}$. Увеличение объема промышленного производства на $1 \%$ приводит к росту величины налогов на $0,667 \%$, а увеличение ВРП на $1 \%$ обусловливает повышение объема налогов на $0,154 \%$, что отражает определяющие значение промышленного производства для налоговой системы. Интересно, что абсолютный рост сельского хозяйства обратно пропорционален росту налогов. С одной стороны это объясняется тем, что максимальный объем продукции сельского хозяйства (урожаи) совпадает с годами финансово-экономических кризисов, а с другой, связан с большим теневым сектором в этой отрасли.

Частный коэффициент детерминации показывает, какая доля результативного признака объясняется вариацией факторных признаков. Он определяется по формуле: $d_{x_{i}}=r_{y x_{i}} \cdot \beta_{x_{i}}$, где $r_{y x_{i}}-$ парный коэффициент корреляции между результативным и факторным признаком; $\beta_{x_{i}}=a_{x_{1}} \frac{\sigma_{x_{i}}}{\sigma_{y}}-$ 
Коэффициенты регрессии, эластичности, детерминации и ква-коэффициента влияния факторных показателей на результативность

[Table 4. Coefficients of regression, elasticity, determination and qua-coefficient of influence of factor indicators on performance]

\begin{tabular}{|l|c|c|c|c|c|c|c|c|c|}
\hline & $a_{0}$ & $a_{1}$ & $a_{2}$ & $\ni_{1}$ & $\ni_{2}$ & $d_{x_{1}}$ & $d_{x_{2}}$ & $Q_{x_{1}}$ & $Q_{x_{2}}$ \\
\hline $\begin{array}{l}\text { ВРП, } \\
\text { промышленность, } \\
\text { сельское хозяйство / } \\
\begin{array}{l}\text { GRP, industry, } \\
\text { agriculture }\end{array}\end{array}$ & 28,88 & 0,872 & 0,943 & 0,735 & 0,248 & 0,679 & 0,311 & 0,318 & 0,146 \\
\hline $\begin{array}{l}\text { ВРП, } \\
\text { промышленность, } \\
\begin{array}{l}\text { торговля / GRP, } \\
\text { industry, trade }\end{array}\end{array}$ & 48,2 & 0,402 & 1,266 & 0,338 & 0,633 & 0,313 & 0,687 & 0,146 & 0,319 \\
\hline $\begin{array}{l}\text { ВРП, } \\
\text { промышленность, } \\
\text { строительство / } \\
\begin{array}{l}\text { GRP, industry, } \\
\text { соnstruction }\end{array}\end{array}$ & $-69,1$ & 0,772 & 3,483 & 0,651 & 0,391 & 0,602 & 0,391 & 0,281 & 0,184 \\
\hline
\end{tabular}

соответствующий коэффициент уравнения множественной регрессии $[3,5]$.

В этой модели изменение объема промышленности обеспечивает 79,0\% вариации налогов, а изменение ВРП лишь 19,5\% вариации налогов.

Для более точной оценки влияния каждого фактора на результативный показатель используется $Q$-коэффициент, определяемый по формуле:

$$
Q_{x_{i}}={ }_{x_{i}} \cdot v_{x_{i}}[2,4],
$$

где $v_{x_{i}}$ - коэффициент вариации факторного признака. $Q_{x_{21}}=0,289, Q_{x_{1}}=0,072$.

В данной модели влияние второго фактора (промышленного производства) является более существенным, также как и по сравнению с любыми отраслями хозяйства в других моделях. Во многом это объясняется тем, что в промышленном производстве и в строительстве доля теневой экономики намного ниже по сравнению с остальными отраслями хозяйства. Поэтому важнейшим фактором повышения эффективности хозяйства ЦЧР, особенно роста налоговой базы, является рост промышленного производства.

На втором этапе было проведено моделирование и интерпретация взаимосвязей между ВРП (y), промышленности $\left(x_{1}\right)$, сельского хозяйства, торговли и строительства $-x_{2}$ (таблица 4 ).

В этих моделях влияние промышленности на ВРП всех коэффициентов значительно выше во всех отраслях, кроме торговли, что тоже не случайно. С одной стороны промышленное производ- ство было более стабильным по сравнению с товарооборотом к колебаниям потребительского спроса и ВРП. С другой стороны торговля в условиях рыночного времени диктует свои условия местным производителям, отнимая у них значительную и даже иногда основную часть прибыли.

\section{ЗАКЛЮЧЕНИЕ}

Корреляционно-регрессионный анализ зависимостей между величиной налогов, объемов ВРП, продукции промышленного производства, сельского хозяйства, оборота торговли и строительных работ за 2005-2016 годы показал наличие тесных связей и пропорций между описываемыми отраслями, среди которых важнейшую роль почти во всех аспектах экономической интерпретации математических моделей играет промышленность. Необходимо отметить, что именно промышленность определяет налоговый потенциал и развитие ВРП в регионах ЦЧР. При этом роль промышленности в образовании валовой добавленной стоимости (ВДС) исключительно велика. В 2017 году в общем объеме ВДС в рыночных ценах ЦЧР (2837,0 млрд. руб.) на промышленность приходилось 847,8 млрд. руб., на сельское хозяйство 456,1 млрд. руб., на строительство-227,6 млрд. руб., на торговлю соответственно - 414,9 млрд. руб. Коэффициент ранговой корреляции между уровнем экономического и промышленного развития на 1 чел. среди регионов ЦЧР за 2018 год составил 0,80. При этом, как мы уже отмечали, торговля от- 
нимает значительную часть ВДС у промышленности (розничные цены в 2-6 раз выше цен производителей), уменьшает ВРП регионов в целом, переводя значительную часть добавленной стоимости в теневую сферу [3]. Более высокая доходность простого бизнеса привлекает к нему большую часть инвестиционного капитала и одновременно повышает его стоимость для других (менее эффективных) отраслей $[3,11]$. Поэтому не развитие торговли и других более выгодных отраслей, а (на основе нашего анализа) преимущественное развитие промышленного сектора хозяйства является экономически наиболее эффективным направлением инвестиционного развития ЦЧР. Для этого необходимо создать механизм инвестиционно-инновационного развития машиностроения и легкой промышленности. В этом случая можно будет значительно повысить уровень самодостаточности и региональной безопасности ЦЧР.

Важное с точки зрения самодостаточности страны в целом интенсивное в последние годы развитие первичных и вторичных отраслей, прежде всего АПК, имеет определяющее значение в современных инвестиционных процессах, происходящих на территории ЦЧР. Повышение уровня развития отраслей первичного сектора, особенно сельского хозяйства, а также низкотехнологичных отраслей обрабатывающей промышленности вторичного сектора, является жизненно необходимым. Для совершенствования хозяйства и достижения экономической и технологической безопасности без развития промышленного производства с высокой добавленной стоимостью, обеспечивающего потребности федерального и региональных рынков не обойтись. Поэтому необходимо создание механизма реиндустриализации района до уровня сбалансированного состояния отраслей хозяйства и высокой реальной занятости населения, так как отрасли промышленности являются «локомотивами» развития всего хозяйства. Необходимо значительное расширение комплексности хозяйства. Например, резервы развития АПК Белгородской области (ведущего в стране) связаны не только с повышением уровня добавленной стоимости пищевой промышленности, но и с развитием отраслей сферы производства средств производства для АПК, которые пока развиты в этой области недостаточно. Основные направления реиндустриализации хозяйства ЦЧР по нашему мнению должны быть направлены на повышение качества и добавленной стоимости продукции АПК, а также ускоренного развития отраслей машиностроения и легкой промышленности, обеспечивающих местные региональные и локальные рынки.

\section{СПИСОК ЛИТЕРАТУРЫ}

1. Жук С.И. Место Воронежской области в производительных силах Центрально-Черноземного экономического района // Вестник Воронежского государственного университета. Серия География. Геоэкология, 2020, № 1, с. 58-66.

2. Крупко А.Э., Михно В. Б. Факторы, проблемы и основные направления устойчивого развития Центрально-Черноземного района // Вестник Воронежского государственного университета. Серия География. Геоэкология, 2019, № 1, с. 55-73.

3. Крупко А.Э., Фетисов Ю. М., Рогозина Р. Е. Моделирование факторов устойчивого развития промышленного производства // Финансы, экономика, стратегия, 2018, № 7, с. 56-66.

4. Крупко А.Э., Рогозина Р. Е., Шульгина Л. В. Проблемы и угрозы устойчивого развития промышленной системы Воронежской области // Финансы, экономика, стратегия, 2017, № 10, с. 41-51.

5. Крупко А.Э., Фетисов Ю. М., Рогозина Р.Е. Интерпретация корреляционно-регрессионного анализа основных факторов развития экономики ЦФО // Финанcbl, экономика, стратегия, 2018, № 12, с. 22-29.

6. Регионы России. Социально-экономические показатели. 2003: Стат. сб. Москва, Госкомстат России, 2003. $895 \mathrm{c}$.

7. Регионы России. Социально-экономические показатели. 2016: Стат. сб. Москва, Росстат, 2016. 1326 с.

8. Регионы России. Социально-экономические показатели. 2018: Стат. сб. Москва, Росстат, 2018. 1402 с.

9. Регионы России. Социально-экономические показатели. 2019: Стат. сб. Москва, Росстат, 2018. 1204 с.

10. Шмойлова Р. А., Минашкин В.Г., Садовникова Н. А., Шувалова Е. Б. Теория статистики. Москва, Финансы и статистика, 2014. 656 с.

11. Ускова Т.В. Управление устойчивым развитием региона. Вологда, ИСЭРТ РАН, 2009. 355 с.

12. Федотов В.И., Куролап С.А., Нестеров Ю.А. Структурные блоки региональной модели устойчивого эколого-экономического развития Центрального Черноземья // Вестник Воронежского государственного университета. Серия География. Геоэкология, 2003, № 2. c. $5-14$.

13. Шульгина Л.В., Гасилов В.В., Сова А.Н. Уnравление экономической устойчивостью промышленных предприятий. Воронеж, ВГТА, 2010. 168 с.

Конфликт интересов: Авторы декларируют отсутствие явных и потенциальных конфликтов интересов, связанных с публикацией настоящей статьи.

Поступила в редакичию 22.10.2019 Принята к публикации 02.06.2020 


\title{
Evaluation and Modeling of the Central Black Soil Region Industry Development in the Post-Soviet Period
}

\author{
A. E. Krupko ${ }^{凶}$, Yu. M. Fetisov \\ Voronezh State University, Russian Federation \\ (1, Universitetskaya pl., Voronezh, 394018)
}

\begin{abstract}
The purpose is to identify the characteristics, trends and factors of industrial development of the Central Black Soil Region. The insufficiently high level of industry in the Central Black Soil Region and the negative long-term trends in its development require a deep analysis of the internal causes of the development of the region's economy. Materials and methods. To achieve this goal, comparative, structural, statistical, mathematical-statistical and analytical research methods were used. The statistical information presented in the official publications of the Federal State Statistics Service - "Regions of Russia" for 2003-2019 was used. To perform the calculations, the statistical data were generalized, systematized, and structured. When modeling factors and development trends of industry, we used traditional types of regression models with their expanded economic interpretations. Mathematical modeling and economic interpretation of its results were carried out on the basis of an analysis of the relationships between the volumes of taxes, GRP, industry, agriculture, trade and the construction of the Central Black Soil Region. Results. An analysis of the coefficients of variation shows that the most stable sector of the economy in the 2000s was industry. In the models determining the development of taxes, the influence of industry on tax potential was predominant. In all models of assessing factors for the development of GRP, the importance of industry was much higher compared to other sectors of economy except trade. Taking into account the realities of modern difficult time, on the basis of our work, we can conclude that the most economically effective direction of investment development of the Central Black Soil Region is the predominant development of the industrial sector of the economy. The main areas of reindustrialization of the economy of the Central Black Soil region, in our opinion, should be aimed at improving the quality and added value of agricultural products, as well as the accelerated development of mechanical engineering and light industry sectors that provide local regional and local markets.
\end{abstract}

Key words: Central Black Soil Region, regression, correlation, interpretation, taxes, gross regional product, industry, agriculture, trade, construction.

For citation: Krupko A.E., Fetisov Yu. M. Evaluation and Modeling of the Central Black Soil Region Industry Development in the Post-Soviet Period. Vestnik Voronezskogo gosudarstvennogo universiteta. Seria Geografia. Geoekologia, 2020, No. 2, pp. 66-74. (In Russ.) DOI: https://doi.org/10.17308/geo.2020.2/2888

\section{REFERENCES}

1. Zhuk S.I. Mesto Voronezhskoy oblasti v proizvoditel'nykh silakh Tsentral'no-Chernozemnogo ekonomicheskogo rayona [The place of the Voronezh region in the productive forces of the Central Black Earth Economic Region]. Vestnik Voronezskogo gosudarstvennogo universiteta. Seria Geografia. Geoekologia, 2020, no. 1, pp. 5866. (In Russ.)

2. Krupko A.E., Mikhno V.B. Faktory, problemy i osnovnye napravleniya ustoychivogo razvitiya Tsentral'no-
Chernozemnogo rayona [Factors, problems and main directions of sustainable development of the Central Black Earth Region]. Vestnik Voronezskogo gosudarstvennogo universiteta. Seria Geografia. Geoekologia, 2019, no. 1, pp. 55-73. (In Russ.)

3. Krupko A. E., Fetisov Yu. M., Rogozina R. E. Modelirovanie faktorov ustoychivogo razvitiya promyshlennogo proizvodstva [Modeling of factors of sustainable development of industrial production]. Finansy, ekonomika, strategiya, 2018, no. 7, pp. 56-66. (In Russ.)

(c) Krupko A.E., Fetisov Yu. M., 2020

区-mail: glomer-a@mail.ru

The content is available under Creative Commons Attribution 4.0 License. 
4. Krupko A. E., Rogozina R. E., Shul'gina L. V. Problemy i ugrozy ustoychivogo razvitiya promyshlennoy sistemy Voronezhskoy oblasti [Problems and threats of sustainable development of the industrial system of the Voronezh region]. Finansy, ekonomika, strategiya, 2017, no. 10, pp. 41-51. (In Russ.)

5. Krupko A. E., Fetisov Yu. M., Rogozina R. E. Interpretatsiya korrelyatsionno-regressionnogo analiza osnovnykh faktorov razvitiya ekonomiki TsFO [Interpretation of the correlation and regression analysis of the main factors of the development of the economy of the Central Federal District]. Finansy, ekonomika, strategiya, 2018, no. 12, pp. 22-29. (In Russ.)

6. Regions of Russia. Socio-economic indicators. 2003. Moscow, Goskomstat Rossii Publ., 2003. 895 p. (In Russ.)

7. Regions of Russia. Socio-economic indicators. 2016. Moscow, Rosstat Publ., 2016. 1326 p. (In Russ.)

8. Regions of Russia. Socio-economic indicators. 2018. Moscow, Rosstat Publ., 2018, 1402 p. (In Russ.)

9. Regions of Russia. Socio-economic indicators. 2019. Moscow, Rosstat 2019. 1204 p. (In Russ.)

10. Shmoylova R.A., Minashkin V.G., Sadovnikova N. A., Shuvalova E. B. Teoriya statistiki [Theory of

Крупко Анатолий Эммануилович

кандидат географических наук, доцент кафедры социально-экономической географии и регионоведения факультета географии, геоэкологии и туризма Воронежского государственного университета, г. Воронеж, ORCID: https://orcid.org/0000-0003-3141-5914, e-mail: glomer-a@mail.ru

Фетисов Юрий Михайлович

кандидат физико-математических наук, доцент кафедры рекреационной географии, страноведения и туризма факультета географии, геоэкологии и туризма Воронежского государственного университета, г. Воронеж statistics]. Moscow, Publ. Finansy i statistika, 2014. 656 p. (In Russ.)

11. Uskova T. V. Upravlenie ustoychivym razvitiem regiona [Management of sustainable development of the region]. Vologda, Publ. ISEDT RAS, 2009. 355 p. (In Russ.)

12. Fedotov V. I., Kurolap S. A., Nesterov Yu. A. Strukturnye bloki regional'noy modeli ustoychivogo ekologo-ekonomicheskogo razvitiya Tsentral'nogo Chernozem'ya [The structural blocks of the regional model of sustainable environmental and economic development of the Central Black Earth Region]. Vestnik Voronezskogo gosudarstvennogo universiteta. Seria Geografia. Geoekologia, 2003, no. 2, pp. 5-14. (In Russ.)

13. Shul'gina L. V., Gasilov V. V., Sova A. N. Upravlenie ekonomicheskoy ustoychivost'yu promyshlennykh predpriyatiy [Management of economic sustainability of industrial enterprises]. Voronezh, VGTA Publ., 2010. 168 pp. (In Russ.)

Conflict of interests: The authors declare no information of obvious and potential conflicts of interest related to the publication of this article.

Received: 22.10 .2019

Accepted: 02.06.2020

\section{Anatoliy E. Krupko}

Cand. Sci. (Geogr.) Assoc. Prof. of the Department of Social and Economic Geography and Regional Studies, Faculty of Geography, Geoecology and Tourism, Voronezh State University, Voronezh, Russian Federation, ORCID: https://orcid.org/0000-0003-3141-5914, e-mail: glomer-a@mail.ru

Yuri M. Fetisov

Cand. Sci. (Phys.-Math.) Assoc. Prof. of the Department of Recreational Geography, Country Studies and Tourism at the Voronezh State University, Voronezh, Russian Federation, e-mail: deanery@geogr.vsu.ru 